\begin{tabular}{l|l}
\hline SISTEMA \\
ELETRONICO \\
DE REVISTAS \\
SER I UFPR
\end{tabular}

\title{
Zona de Educação para o Ecodesenvolvimento: aproximação da Universidade com a Comunidade
}

\author{
Education Zone for Ecodevelopment: Approximation \\ between the University and the Community
}

\author{
Liliane Cristine Schlemer ALCÂNTARA ${ }^{1 *}$, Valdinho PELLIN ${ }^{1}$, Carlos Alberto Cioce SAMPAIO ${ }^{1}$, Cristiane \\ Mansur de Moraes SOUZA ${ }^{1}$ \\ ${ }^{1}$ Programa de Pós-Graduação em Desenvolvimento Regional (PPGDR), Universidade Regional de Blumenau (FURB), Blumenau, SC, Brasil. \\ *E-mail de contato: lilianecsa@yahoo.com.br
}

Artigo recebido em 2 de abril de 2014, versão final aceita em 3 de outubro de 2014.

RESUMO: Diante da problemática ambiental, o ecodesenvolvimento e os arranjos socioprodutivos de base comunitária (APLs.Com) se apresentam como uma estratégia de conservação de modos de vida e da biodiversidade, oportunizando às pequenas comunidades geração de trabalho e renda e desenvolvimento local. Tem-se como objetivo sistematizar o esforço de pesquisa ao redor de uma Zona de Educação para o Ecodesenvolvimento (ZEE), Morretes, Paraná, e analisar o papel da universidade enquanto indutor de desenvolvimento territorial. Valeu-se da pesquisa documental a partir de relatórios de estágio, dissertações e tese, projetos de pesquisa e extensão, derivados de estudos e práticas realizados na ZEE, ocorrida entre os anos de 2006 e 2014. Identificaram-se neste período três relatórios de estágio, doze dissertações, uma tese, dezenove projetos de pesquisa e onze de extensão. Verificou-se o importante papel da universidade nas discussões relacionadas ao desenvolvimento territorial, utilizando-se principalmente de abordagem interdiciplinar, com vocação transdiciplinar, característica das ZEE, sendo possível integrar teoria e prática e, portanto, contribuindo significativamente para fomentar o desenvolvimento em localidades com vulnerabilidades.

Palavras-chave: desenvolvimento territorial; ecodesenvolvimento; arranjo socioprodutivo de base comunitária; interdisciplinaridade; universidade.

ABSTRACT Given the environmental problems, ecodevelopment and the social and productive organization of the Community (APLs.Com) seem to be a strategy for the conservation of live style and biodiversity, offering small communities the opportunity to promote income and local development. The purpose is e to systematize research efforts around an Education Zone for Ecodevelopment (ZEE), in Morretes, Paraná, analyzing the role of the university as a promoter of territorial development. We revised many documents, including internship reports, dissertations, thesis, research projects and other works, which were produced as a result of studies and practices conducted in the ZEE, between 2006 and 2014. During this period, we identified three reports, twelve essays, one thesis, nineteen research projects and eleven extension projects. We noticed the important role of university in discussions related to territorial development, mainly using a cross-discipline approach to 
trans-disciplinary vocation, a characteristic of ZEE, which enabled the integration between theory and practice, significantly contributing to the promotion of development in territories with vulnerabilities.

Keywords: territorial development; ecodevelopment; socioproductive organization of communities; crossdiscipline; university.

\section{Introdução}

A noção de território e desenvolvimento territorial surge do entendimento formado pela dinâmica de atores sociais que ocupam espaço determinado, nomeado na forma de identidade individual e social, com referenciais familiares e profissionais. Territórios são: “[...] entidades socioespaciais, ou relacionadas às atividades humanas conduzidas num dado espaço". [...] o desenvolvimento territorial faz referência a espaço geográfico que não é dado, mas construído. "Construído pela história, por uma cultura e por redes sociais que desenham suas fronteiras" (Jean, 2010, p. 51).

Territórios são realidades em movimento, nas quais imperam as relações sociais. Noção de território designa o resultado da confrontação dos espaços individuais dos atores nas suas dimensões econômicas, socioculturais e ambientais (Carriàre \& Cazella, 2006, p. 33). Territórios são resultados da maneira como as sociedades se organizam para usar sistemas naturais em que se apóia sua reprodução, o que abre interessante campo de cooperação entre ciências sociais e naturais no conhecimento desta relação (Abramovay, 2010, p. 30).

$\mathrm{O}$ território tem que ser entendido como território usado, no sentido que possui identidade, que significa sentimento de pertencer àquilo que nos parece pertencer. Território é fundamento do trabalho, lugar da residência, das trocas materiais e espirituais e exercício da vida (Becker \& Santos, 2007).

Partindo deste pressuposto, teve-se como objetivo sistematizar o esforço de pesquisa ao redor de uma Zona de Educação para o Ecodesenvolvimento (ZEE), no litoral centro sul, e analisar o papel da universidade enquanto indutor de desenvolvimento territorial.

Acredita-se que a relevância desta pesquisa se dá a partir da promoção de uma reflexão acerca dos esforços desprendidos das universidades em se aproximar das demandas reais comunitárias, diante das críticas de seu distanciamento. A pesquisa justifica-se pela importância de um estudo mediante aprofundamento dos temas, na busca de mecanismos de adaptação e tentativa de superação de vulnerabilidades socioeconômicas locais, quando identificados seus problemas e propostas soluções, estimulando competências e autonomia nas comunidades rurais em prol de um desenvolvimento territorial.

A universidade pode desempenhar papel importante na medida em que tem a possibilidade de oferecer subsídios relevantes para transformações em grande escala nos padrões culturais dominantes (Vieira \& Fon$\tan , 2011$, p. 24).

Para realizar este estudo, foi efetuada busca em relatórios de estágio, trabalhos de dissertação e tese, projetos de pesquisa e de extensão realizados no litoral Centro Sul do Paraná, envolvendo os temas de ecodesenvolvimento e arranjos socioprodutivos de base comunitária (APL.Com).

O trabalho inicia com a apresentação dos procedimentos metodológicos. Na sequência aborda uma breve discussão sobre desenvolvimento territorial e caracterização do ecodesenvolvimento, destacando a contribuição de Ignacy Sachs quanto suas dimensões de sustentabilidade. Posteriormente aborda a temática dos arranjos socioprodutivos de base comunitária, termo designado e disseminado pelos Núcleos de Ecossocioeconomia da Universidade Federal do Paraná (UFPR), de Políticas Públicas da Pontifícia Universidade Católica (PUC/PR) e da Fundação Universidade Regional de Blumenau (FURB). Em seguida discutem-se resultados da pesquisa bibliográfica sistematizada realizada sobre os estudos e práticas na Zona de Educação para o Ecodesenvolvimento, para então apresentar as conclusões.

\section{Procedimentos metodológicos}

Valeu-se de pesquisa descritiva e analítica e do esforço de pesquisa-ação ao redor de uma Zona de 
Educação para o Ecodesenvolvimento (ZEE), Morretes, Paraná, em torno da interação entre conhecimento científico - processo interdisciplinar com base cartográfica, pesquisas e interpretações / leitura dos dados levantados - e sabedoria tradicional - A valorização da sabedoria tradicional e o estímulo à participação de informantes-chave foi desenvolvida por meio de oficinas, conversas e caminhadas geoambientais, onde a comunidade desempenhou o papel principal na construção do conhecimento, definindo aspectos importantes e colaborando como facilitadores. O estudo foi de corte longitudinal, sendo que o período analisado compreende os anos de 2006 a 2014.

Este estudo realizou uma pesquisa documental sistematizada, identificando relatórios de estágio, projetos de pesquisa, extensão, dissertação e tese, realizadas na Zona de Educação para o Ecodesenvolvimento (ZEE), criada em 2006, na Microbacia Hidrográfica de Rio Sagrado, no litoral Centro Sul, no qual duas palavras-chave se destacam ecodesenvolvimento e arranjo socioprodutivo de base comunitária (Apl.Com).

Foram identificados 03 (três) relatórios de estágio, 11 (onze) projetos de extensão, 16 (dezesseis) projetos de pesquisa, 12 (doze) dissertações de mestrado e 01 (uma) tese de doutorado (em andamento), desenvolvidos nos Curso de Graduação e de Programa de Pós-graduação da Universidade Regional de Blumenau (FURB), Universidade Federal do Paraná (UFPR) e da Universidade Austral do Chile.

\section{Introduzindo o Ecodesenvolvimento a partir do Desenvolvimento Territorial}

Para Jean (2010), o conceito de desenvolvimento territorial rompe com uma tradição mais antiga de estudos sobre o desenvolvimento regional e não dispõe ainda de um arcabouço doutrinário ou de teorias já estabilizadas. Articula duas noções: desenvolvimento e território. O território não se define por sua escala, e sim pelo modo de organização e pela maneira segundo a qual os atores constitutivos dos territórios conseguem coordenar suas ações. Corroborando com Jean (2010), Pecqueur (2005) destaca que o desenvolvimento territorial designa todo processo de mobilização dos atores que leve à elaboração de uma estratégia de adaptação aos limites externos, na base de uma identificação coletiva com uma cultura e um território.

Schneider (2004, p. 99) compreende o território enquanto "um espaço de ação em que transcorrem as relações sociais, econômicas, políticas e institucionais. Esse espaço é construído a partir da ação entre os indivíduos e o ambiente ou contexto objetivo em que estão inseridos". Neste sentido, percebe-o como dinâmico, em constante transformação e mudança. Esse dinamismo é configurado tanto pelos atores internos e suas inter-relações, como pela relação com fatores externos. Resultado de uma construção social e coletiva, o território é considerado o espaço apropriado por um determinado grupo que compartilha valores culturais, e se torna foco do desenvolvimento, não sendo apenas o espaço físico, mas também ator desse processo.

É possível observar, portanto, que a noção de território transpassa a questão geográfica. Nela inserem-se, por exemplo, os atores e as relações institucionais que os interrelacionam. Para Carriàre \& Cazella (2006), os territórios são realidades em movimento, nas quais prevalecem relações sociais. A noção de território designa o resultado da confrontação dos espaços individuais dos atores nas suas dimensões econômicas, socioculturais e ambientais.

Para Beduschi Filho \& Abramovay (2004), os territórios não podem ser entendidos simplesmente como um conjunto neutro de fatores naturais e dotações humanas capazes de determinar as opções de localização de empresas e dos trabalhadores. Os territórios se constituem por laços informais, por modalidades não mercantis de interação construídas ao longo do tempo e que moldam uma certa personalidade e, portanto, uma das fontes da própria identidade dos indivíduos e grupos sociais.

Território é onde se formam as visões de mundo, e não simplesmente, se projetam visões preestabelecidas. É onde se dá origem as estruturas de governança, que evidenciam a intenção dos indivíduos de serem protagonistas, ao invés de passivos observadores da ação da mão invisível ou eternos dependentes do Estado de providência. Território é onde as pessoas produzem e trocam, competem e cooperam (Ortega \& Jeziorny, 2011).

A importância das discussões em torno do território emerge com o avanço da globalização. Sacco dos Anjos 
et al. (2013) destacam que a necessidade de cooperar e de construir arranjos pactuados é cada vez maior em meio a um contexto de globalização. As novas tecnologias de informação, comunicação e transporte repercutem, cada vez mais, sobre todos os territórios e âmbitos da vida social, produzindo a anulação do espaço pelo tempo, acirrando a competitividade e a exposição do tecido socioprodutivo e a lógica das relações de mercado.

Entende-se, portanto, que a busca por estratégias voltadas a identificação das capacidades territoriais torna-se importante. Para Freitas Santos \& Cadima Ribeiro $^{1}$ (2012), em uma economia cada vez mais global e competitiva, nem todos os territórios possuem os recursos e capacidade necessária à competição com outros territórios, cujas estruturas apresentam condições mais competitivas. Em qualquer país é possível encontrar territórios mais dotados de recursos e competências do que outros. Deste modo, é importante perceber e identificar os recursos e capacidades que os territórios dispõem para que possam gerar mais-valias no mercado. É necessário, então, que as capacidades empreendedoras dos agentes locais sejam mobilizadas para transformar essas capacidades em um diferencial competitivo.

O entendimento é que regiões e lugares, a partir de suas especificidades e potencialidades, podem encontrar formas de transformação de suas realidades em busca de melhoria da qualidade de vida a partir dos processos globais (Caldas, 2003).

Neste contexto, é possível destacar os Arranjos Produtivos Locais com foco no ecodesenvolvimento como estratégias que, se bem conduzidas, podem contribuir para o fortalecimento das economias locais.

\subsection{Enfim o Ecodesenvolvimento}

Discussões acerca do atual modelo de desenvolvimento emergem da consciência humana de conservar o meio ambiente, a fim de garantir a sobrevivência das próximas gerações. O atual modelo de desenvolvimento é visto como excludente e que gradativamente poderia ser substituído por um modelo que se baseie em tripé, compreendendo as dimensões sistêmicas do desenvolvimento, sua sustenbalidade econômica, social e ambiental. Para Dallabrida (2000, p. 25):

Ao analisar o atual padrão de desenvolvimento, é possível identificar sinais incontestáveis de insustentabilidade: expressa na degradação ambiental, nas desigualdades sociais e na centralização do poder. Ainda se fundamenta na crença equivocada de que o capital natural à disposição no planeta Terra é infinito, capaz de sustentar um crescimento econômico ininterrupto, e priorizar os empreendimentos grandiosos.

Este debate em torno da necessidade de substituir o modelo de desenvolvimento vigente foi discutido em Estocolmo durante a Conferência das Nações Unidas sobre Meio Ambiente Humano e ratificado na Conferência sobre Meio Ambiente e Desenvolvimento realizada em Johannesburgo, na África do Sul, em 2002. Coube a Maurice Strong cunhar o termo ecodesenvolvimento em 1973.

\footnotetext{
Por meio deste conceito, buscava-se caracterizar uma "ideia-força" que fosse capaz de direcionar, de forma criativa, iniciativas de dinamização socioeconômica sensíveis aos fenômenos da degradação do meio ambiente e da marginalização social, cultural e política (Sachs, 1986b; Vieira, 1995).
}

A fundamentação e disseminação do conceito de ecodesenvolvimento ${ }^{2}$ deveram-se muito aos esforços da equipe do pesquisador Ignacy Sachs à frente do Centre International de Recherche sur I'Environnement et Le Développement (CIRED), em Paris. Ele pode ser considerado um dos autores pioneiros no reconhecimento de que a crise ambiental constitui uma expressão particu-

1 Os professores Freitas Santos \& Cadima Ribeiro do Instituto Politécnico do Porto e da Universidade do Minho, respectivamente, discutem em seus artigos e pesquisas questões relacionadas aos impactos econômicos da região de origem nos produtos do território.

2 O Núcleo Interdisciplinar de Pesquisa e Formação sobre Meio Ambiente e Desenvolvimento, filiado ao Programa de Pós-Graduação em Sociologia Política da UFSC, vem trabalhando à luz do enfoque do ecodesenvolvimento desde 1989. As iniciativas em curso dos pesquisadores estão concentradas em três grandes áreas : Teoria e Métodos para a Pesquisa Ambiental; Desenvolvimento, Meio Ambiente e Qualidade de Vida na Região Sul do Brasil e Educação Ambiental como Fator de Desenvolvimento Urbano e Rural (Vieira et al., 1998). 
larmente virulenta das contradições fundamentais embutidas nos estilos de desenvolvimento contemporâneos (Vieira et al., 1998). Para Vieira (2009, p. 27):

Desde o final dos anos sessenta, a eclosão de uma problemática planetária relacionada ao reconhecimento de "limites ecológicos do crescimento material" tem mobilizado uma atenção crescente das comunidades científicas e da opinião pública. O conceito sistêmico do ecodesenvolvimento emergiu deste contexto e disseminou-se gradativamente como expressão de uma crítica radical da ideologia economicista subjacente a suposta "civilização" industrial-tecnológica.

A versão inicial foi reelaborada por Ignacy Sachs (1974), considerado clássico da literatura ecológica-política. A problemática ambiental continua a ser pensada como potencial de recursos disponíveis no contexto ecológico e social, associado ao saber tradicional das populações. O conceito designa um enfoque participativo de planejamento e gestão de estratégias plurais de intervenção, adaptadas a contextos socioculturais e ambientais específicos (Sachs, 1986b; Vieira, 1995).

Segundo o capítulo 35 da Conferência das Nações Unidas sobre Meio Ambiente e Desenvolvimento, uma das bases para a ação exigida do desenvolvimento sustentável é "[...] assumir perspectivas de longo prazo, integrar os efeitos locais e regionais das mudanças mundiais no processo de desenvolvimento e utilizar os melhores conhecimentos científicos e tradicionais disponíveis" (CNUMAD 2014, p. 2).

Embora se discuta se ecodesenvolvimento e desenvolvimento sustentável sejam sinônimos ou não (Baroni, 1992), se aceita quatro postulados que reúnem ideias essenciais do enfoque de ecodesenvolvimento, para que não se tenha dúvidas de que tipo de desenvolvimento se quer promover: finalidades sociais; self-reliance ${ }^{3}$; relação de simbiose com a natureza e eficácia econômica socioambiental (Sachs, 1986b; Vieira, 1992).

De acordo com Sachs (2007, p. 15), o desenvolvimento sustentável está alicerçado pelos "pilares social-ambiental-territorial-econômico-político", levando à compreensão de que o conceito implica na interdisciplinaridade desses diversos campos. O ecodesenvolvimento, para Sachs (2007), representa a perspectiva possível de desenvolvimento dos trópicos, economicamente viável, ecologicamente prudente, socialmente justo, autoconfiante e autocentrado economicamente. De caráter endógeno, em alternativa ao economicismo e com outra ótica de mercado, valoriza os recursos de cada região [ecorregiões] para satisfazer as necessidades básicas da população. Leff aponta a viabilidade do desenvolvimento sustentável como,

um dos maiores desafios históricos e políticos do nosso tempo. Dali surgiu o imperativo de ecologizar a economia, a tecnologia e a moral. Nessa perspectiva se inscrevem as tentativas da economia neoclássica para internalizar as externalidades ambientais com os critérios da racionalidade econômica, ou os da economia ecológica para fundar um novo paradigma, capaz de integrar os processos ecológicos, populacionais e distributivos aos processos de produção e consumo. [...] (Leff, 2006, p. 223).

A crise socioambiental evidencia a insustentabilidade ecológica e social da racionalidade econômica. "Daí o propósito de internalizar as externalidades socioambientais do sistema econômico ou de submeter o processo econômico às leis ecossistêmicas nas quais se inscrevem" (Leff, 2006, p. 226). O desafio é de compatibilizar políticas econômicas e ambientais e evoluir no sentido do Desenvolvimento Sustentável.

O ecodesenvolvimento é um estilo de desenvolvimento que, em cada região, sugere soluções específicas de seus problemas particulares, levando em conta dados ecológicos e culturais, necessidades imediatas como também de longo prazo. Prega participação efetiva das populações locais na realização das estratégias de ecodesenvolvimento. A participação é indispensável para definição das potencialidades locais e organização do esforço coletivo com vistas ao aproveitamento destas potencialidades locais (Sachs, 1986a).

Designa, em primeiro momento, um estilo de desenvolvimento aplicável a projetos localizados não só

3 Self-reliance significa contar com suas próprias forças, na sua autonomia de escolha e na sua tomada de decisão (Sachs, 1986b). 
em áreas rurais, mas também em áreas urbanas, oposto à diretriz mimético-dependente tradicionalmente incorporada pelos países, chamados subdesenvolvidos ou em desenvolvimento, orientado prioritariamente pela busca de satisfação de necessidades básicas e pela promoção da autonomia (self-reliance) das populações envolvidas no processo de desenvolvimento. Em um segundo momento, o conceito de ecodesenvolvimento designa também o enfoque de planejamento participativo de estratégias plurais de intervenção, adaptadas a contextos socioculturais e ambientais específicos (Sachs, 1986b; Vieira, 1995).

Neste sentido, ecodesenvolvimento sugere também "a questão de um desenvolvimento alternativo nos países ditos desenvolvidos, sugerindo a substituição do objetivo de maximização da produção material pelo objetivo de maximização do bem-estar geral, num horizonte de harmonização progressiva das relações sociedade-natureza" (Raud, 1998, p. 257).

De acordo com Sachs (1993), este tipo de desenvolvimento considera simultaneamente cinco dimensões de sustentabilidade: Sustentabilidade Social que é a criação de processo de desenvolvimento civilizatório, baseado no "ser" e que seja sustentado por maior equidade na distribuição do "ter", nos direitos e condições das amplas massas da população, e achatar a distância entre padrões de vida dos mais ricos e mais pobres; Sustentabilidade Econômica que pretende possibilitar melhor alocação e gestão mais eficiente dos recursos e de fluxo regular de investimentos públicos e privados. A eficiência é macrossocial, reduzindo custos sociais e ambientais, diferente da lógica economicista; Sustentabilidade Ecológica incrementa o aumento da capacidade de recursos naturais, limitando os recursos não renováveis ou ambientalmente prejudicáveis, reduzindo o volume de poluição, autolimitando o consumo de material pelas camadas sociais mais privilegiadas, intensificando as pesquisas de tecnologias limpas e definindo regras para uma adequada proteção ambiental; Sustentabilidade Espacial é voltada a configuração rural - urbana mais equilibrada com ênfase nas seguintes questões: concentração excessiva nas áreas urbanas, processos de colonização descontrolados, promoção de projetos modernos de agricultura regenerativa e agroflorestamento, industrialização centralizada, criação de empregos rurais não agrícolas e estabelecimento de rede de reservas naturais e de biosfera para proteger a biodiversidade, e Sustentabilidade Cultural que engloba as raízes endógenas dos modelos de modernização e dos sistemas rurais integrados de produção, respeitando a continuidade das tradições culturais, e até mesmo a pluralidade das soluções particulares (Sachs, 1993).

Portanto, ecodesenvolvimento apresenta-se como novo estilo de desenvolvimento que não centraliza suas atenções apenas para o desenvolvimento econômico, mas também busca o desenvolvimento social e ambiental além de pregar a participação comunitária como ponto importante quando se planejam ações de desenvolvimento. Outro ponto importante é o fato de privilegiar as potencialidades locais e objetivar o fortalecimento das regiões com suas próprias forças endógenas.

Analisando a natureza das cinco dimensões de sustentabilidade defendidas por Sachs é possível afirmar que projetos de ecodesenvolvimento precisam ser pensados de forma multi, inter e transdiciplinar.

A multidisciplinaridade consiste no agrupamento de várias disciplinas para estudar um tema comum sem que exista necessariamente articulação entre elas e a interdisciplinaridade busca justamente essa articulação. A transdisciplinaridade, por sua vez, vai mais além ao tentar articular uma nova compreensão da realidade entre e para além das disciplinas especializadas, ou seja, ir além de uma forma de conhecimento já estabelecida (Paul, 2011).

Morin (1996) destaca que a transdisciplinaridade é vista como alternativa para lidar com situações complexas. Ao mesmo tempo, importa introduzir critérios ecológicos e um quadro interdisciplinar alinhado com enfoque sistêmico e global das realidades para identificar projetos locais, que promovam um modo de conhecimento capaz de apreender os objetos em seu contexto, complexidade e conjunto (Morin, 1996).

Para Leff (2000, p. 22), “[...] a interdisciplinaridade implica assim um processo de inter-relação de processos, conhecimentos e práticas que transborda e transcende o campo da pesquisa e do ensino no que se refere estritamente às disciplinas científicas e suas possíveis articulações".

Garcia (1994) avança nas discussões e afirma que o grande desafio destas abordagens é como articular a participação de pesquisadores de várias disciplinas na 
prática e articular as próprias disciplinas transformando a investigação em interdisciplinar de fato. Deste modo, cada observador, cujas percepções são ampliadas devido à variadas articulações, possibilita conhecimento cada vez mais significativo e abrangente da realidade local.

Novas atitudes precisam ser reconhecidas como pontos básicos para uma revisão nas práticas pedagógicas e nas áreas do conhecimento em todos os níveis de ensino, adotando metodologias e instrumentos que objetivem desenvolver nos estudantes o pensamento de contexto oportunizando a análise multidimensional das questões ambientais e a busca de alternativas metadisciplinares, solidárias e inclusivas para seu equacionamento, na perspectiva local, regional e planetária (Morin, 2003).

Vieira (1999) indica proliferação de experiências de educação ambiental em curso nas diversas regiões do planeta, mas que em sua concepção permanecem fragmentadas. A educação para o ecodesenvolvimento constitui um processo que ainda está em maturação, mas que engloba necessariamente duas dimensões, a saber: (1) a difusão integrada dos saberes científicos e tradicionais acumulados; (2) a modificação das percepções e comportamentos cotidianos por meio da experimentação criativa.

Para Vieira (2007), o enfoque de ecodesenvolvimento na implementação de estratégias depende da capacidade de promover a experimentação com novos sistemas de planejamento e gestão integrada e participativa, bem como, condicionada a reforma profunda nas práticas educativas convencionais. Evidencia a necessidade de dotar o conceito de educação para o ecodesenvolvimento como alicerce desta nova construção com processos que são ao mesmo tempo, igualitários, participativos, frugais, pluralistas e promotores da descentralização e do empoderamento.

Porém, como destacam Vieira \& Ribeiro (1999), embora não se neguem os esforços realizados para tornar realidade os princípios do desenvolvimento sustentável, sobretudo por meio de experiências de criação de agendas 21 locais, parece haver consenso entre pesquisadores de que se trata de algo ainda incipiente. No momento atual, seria conveniente pressupor que nós saberemos o que é desenvolvimento durável (apenas) quando o tivermos realizado.

No entanto, é possivel observar discussões importantes que caminham no sentido de, pelo menos, fortalecer e disseminar questões voltadas à conservação ambiental e à modificação nos padrões de consumo ${ }^{4}$. Deste modo, para desenvolver uma capacidade de reflexão e a mobilização dos atores rumo a educação para o ecodesenvolvimento, faz-se necessário desenvolver competências.

Para Coudel \& Tonneau (2010, p. 451), “uma competência equivale a um poder para agir, não em termos absolutos, mas em função da especificidade de cada situação no espaço e no tempo". Em resumo, além de dispor de saberes (conhecimentos), um ator deve saber fazer (competências) e também se lançar na ação (competências efetivamente mobilizadas para a ação territorial). A construção de competências organiza-se em torno de três eixos principais:

\begin{abstract}
Por um lado, esta construção deve levar em conta a aquisição e a valorização de conhecimentos teóricos e práticos; por outro lado, ela deve organizar a aprendizagem e a mobilização de conhecimentos para desenvolver as competências, pensadas como um conjunto de conhecimentos, atitudes, capacidades e aptidões que habilitam alguém para vários tipos de desempenho na vida; e finalmente; ela favorece um tipo de mobilização de competências específicas realistas e eficazes, tendo em vista a realização de projetos de intervenção (Coudel \& Tonneau, 2010, p. 453).
\end{abstract}

Neste contexto, projetos são usados como suporte da formação na educação para o ecodesenvolvimento

\footnotetext{
4 Um exemplo disso pode ser observado nas discussões voltadas à necessidade de quantificar economicamente e contabilmente os serviços produzidos pelo ecossistema em razão de que esses serviços contribuem sensivelmente para o bem estar humano e não são contabilizados pela economia (Boydb \& Banzhaf, 2007) (Fischer et al., 2009). Além disso, Lenzen et al. (2006) instigam outra discussão importante relacionada ao consumo sustentável. Para os autores, os produtores e consumidores deveriam, dentro de uma economia ecológica, compartilhar as responsabilidades ambientais. Os autores também defendem a necessidade de calcular a pressão do ser humano sobre o planeta, medindo a rapidez com que se consome recursos naturais e se produzem resíduos em comparação com a capacidade que o planeta tem de absorver esses resíduos e gerar novos recursos, numa ação chamada de biocapacidade.
} 
criando e "mobilizando conhecimentos métodos, qualidades e atitudes" (Coudel \& Tonneau, 2010, p. 453). Nessa dinâmica, a realização de projetos voltados à "construção de competências" é capaz de viabilizar a construção de mecanismos que levem atores às dinâmicas de inovação contínua e de valores compartilhados.

\section{Arranjo socioprodutivo de base comunitária (APL.Com)}

A desigualdade no Brasil tem raízes históricas. Não se trata apenas de desigualdade na distribuição de renda, mas também de riquezas, concentração de capital. "O capitalismo é o modo de produção em que os meios de produção e distribuição, assim como o trabalho, se tornam mercadorias, apropriadas privadamente." (Singer, 2000, p. 11).

Acumulação só contribuiu para processo de ampliação das desigualdades e precarização das condições de trabalho com enfraquecimento da legislação trabalhista e do poder dos sindicatos. Ou seja, embora se tenha dinâmica econômica, a divisão de seus ganhos equitativamente não ocorre. Atualmente ocorre reprodução das desigualdades. Surgem novas categorias e conceitos: "nova pobreza, exclusão, vulnerabilidade social, redes de proteção e ações afirmativas" (Asseburg \& Gaiger, 2007, p. 2).

Há necessidade de mudanças no modelo capitalista vigente para um modo de produção mais solidário: “[...] um modo de produção e distribuição alternativo ao capitalismo, criado e recriado periodicamente pelos que se encontram ou temem ficar marginalizados no mercado de trabalho" (Singer, 2000, p. 13). Laville (2002) aponta a Economia Solidária como este modo de produção, como um fato associativo, composto por dimensão econômica, social e política. Articulação dessas dimensões seria permanente e elas estariam fortemente imbricadas, de maneira que não se pode tratar nada desse fenômeno sem considerar todas elas simultaneamente.

O Ministério da Ciência e Tecnologia - MCT - no final da década de 1990, lança o termo Arranjo Produtivo Local, como sendo estágio anterior ao que se denomina sistema produtivo e inovativo local (RedeSist). No Brasil, o primeiro a adotar a abordagem de Arranjos
Produtivos Locais (APLs) foi o Ministério da Ciência e Tecnologia - MCT no final da década de 1990 (Lastres, 2007). Conforme a definição proposta pela RedeSist, APLs são:

aglomerações territoriais de agentes econômicos, políticos e sociais - com foco em um conjunto específico de atividades econômicas - que apresentam vínculos mesmo que incipientes. Geralmente envolvem a participação e a interação de empresas - que podem ser desde produtoras de bens e serviços finais até fornecedoras de insumos e equipamentos, prestadoras de consultoria e serviços, comercializadoras, clientes, entre outros - e suas variadas formas de representação e associação. Incluem também diversas outras instituições públicas e privadas voltadas para: formação e capacitação de recursos humanos (como escolas técnicas e universidades); pesquisa, desenvolvimento e engenharia; política, promoção e financiamento (Lastres \& Cassiolato, 2003a, p. 27).

Os APLs desenvolvem suas atividades de forma articulada por lógica socioeconômica comum que aproveita as economias externas, binômio cooperação-competição, identidade sociocultural do local, confiança mútua entre os agentes do aglomerado, organizações ativas de apoio para a prestação de serviços, fatores locais favoráveis (recursos naturais, recursos humanos, cultura, sistemas cognitivos, logística, infraestrutura etc.), capital social e capacidade de governança da comunidade.

\footnotetext{
Assim, a ênfase em sistemas e arranjos produtivos locais privilegia a investigação das relações entre conjuntos de empresas e destes com outros atores; dos fluxos de conhecimento, em particular, em sua dimensão tácita; das bases dos processos de aprendizado para as capacitações produtivas, organizacionais e inovativa; da importância da proximidade geográfica e identidade histórica, institucional, social e cultural como fontes de diversidade e vantagens competitivas (Lastres \& Cassiolato, 2003b, p. 20).
}

O Arranjo Produtivo Local (APL) ou empreendimento coletivo pode ser considerado como gestão interorganizacional de um espaço territorial sociopolítico-econômico que desencadeia uma dinâmica dialética en- 
tre cooperação e competição, com foco em um conjunto específico de atividades econômicas (Sachs, 2003).Uma das principais vantagens do foco em APLs está no fato de que esta abordagem vai além das tradicionais visões do sistema produtivo, firmando um vínculo entre atividades produtivas e o território.

O conceito de APLs. Com aproxima fortemente a visão de uma aglomeração de produtores ao conceito de território, como um espaço resultante de uma construção sociopolítica, na qual há projetos discordantes, mas sinalizando pela necessidade de se construir as bases de um efetivo pacto territorial de base comunitária em prol do desenvolvimento da localidade e da região, sobrepujando interesses deletérios e endogeneizando centros decisórios (Costa, 2007, p. 129).

Essa expressão, com ênfase associativa comunitária, é adotada por ser considerada um termo menos ideológico, e por subentender que modos mais solidários - tanto na produção quanto de distribuição - surgem no nível comunitário. Entende-se que a comunidade é um tema transversal à questão da territorialidade, como a questão de gênero e pobreza, isto é, um problema global. Contudo, evidencia-se a importância de ação territorial (Sampaio et al., 2005).

Trata-se de experiências qualificadas como participativas e associativas, nas quais ainda predomina reconhecimento do território, valorizando-se o conhecimento tradicional-comunitário. Portanto, quando se trata de arranjo socioprodutivo se está privilegiando grupos organizados ou quase organizados, articulados, chamados de empreendimentos compartilhados, e que sobrevivem sob a égide da economia de mercado; entretanto, preservando sua dinâmica comunitária (Sampaio et al., 2008).

Sampaio (2010a, p. 46) lembra que "[...] trata-se de agregar valor aos pequenos socioempreendimentos e, assim aumentar as possibilidades de sobrevivência socioempresarial diante de uma economia de mercado". No caso de arranjo socioprodutivo de base comunitária é necessário fomentar organizações autogestionárias.

O arranjo socioprodutivo de base comunitária tem como desafio criar e manter a gestão participativa corporativa sob o signo de uma identidade que gere sentimento de pertencimento, facilite a intercooperação e se expanda à identidade cooperativa no plano político institucional na governança cooperativa - e no plano organizacional - na gerência operativa (p. 48).

A autogestão se dá no exercício do poder coletivo na tomada de decisão sobre processos e resultados do trabalho desde a aquisição até distribuição de renda, estimulando a descentralização do poder e responsabilidade compartilhada.

Arranjos socioprodutivos podem ser considerados como estratégia que fomenta comunidades tradicionais a protagonizarem seus modos de vida próprios e definirem os rumos do seu próprio processo de desenvolvimento, tornando-se alternativa possível à sociedade de consumo que se deseja menos hegemônica (Sampaio et al., 2008).

\section{Resultados e discussões}

A partir do binômio desenvolvimento territorial e meio ambiente, abrangendo toda sua complexidade, processos de construção de conhecimentos em ação territorial surgem em Zonas de Educação para o Ecodesenvolvimento, que são compostas por regiões laboratórios, como ocorre no Litoral do Paraná (Rio Sagrado, em Morretes). Regiões laboratórios são espaços que oportunizam o diálogo e inserção de diferentes pesquisadores, bem como novas práticas pedagógicas, diálogo entre atores sociais múltiplos, formação para a cidadania, disponibilização de dados confiáveis e construção de projetos em rede (Lévêque et al., 2000).

Zonas de Educação para o Ecodesenvolvimento (ZEEs), por sua vez, são espaços em que se "[...] privilegia o conhecimento, a compreensão, a proposição e o agir sobre o território de maneira que se conservem modos de vida tradicionais e se preserve a biodiversidade." (Sampaio et al., 2010b, s.p.). Trata-se de um espaço que busca o protagonismo dos sujeitos, incentivando a reflexão intergeracional e o agir de maneira local conectado ao pensar de maneira global. São ainda, espaços de educação não formal, onde os estudos partem de problemas reais vivenciados pela comunidade afetada, e que devem ser resolvidos por seus próprios sujeitos a partir de como eles próprios sentem seus territórios. 
A experiência, objeto de análise neste artigo, insere-se no âmbito do projeto intervivência universitária, intitulado Programa de Honra de Estudos e Práticas de Ecossocioeconomia ${ }^{5}$, na qual obteve financiamento do Edital 23/2008 pelo Conselho Nacional de Desenvolvimento Científico e Tecnológico (CNPq)/Ministério da Ciência e Tecnologia (MCT) conjuntamente com o Fundo Setorial do Agronegócio (CT-Agronegócio)/Ministério do Desenvolvimento Agrário (MDA), edital este encampado pela Universidade Regional de Blumenau (FURB) e Universidade Federal do Paraná (UFPR). Esta prática está fundamentada no objetivo de aproximar a comunidade da universidade, admitindo a importância da conexão entre conhecimentos tradicionais e científicos na busca por soluções integrais a problemas cotidianos inerentes à própria sociedade complexa em que se vive.

Dedobrou-se ainda em um programa de extensão, intitulado "Diagnóstico Socioambiental Participativo da Microbacia do Rio Sagrado", no qual utilizou a bacia hidrográfica como unidade de planejamento, tendo como objetivos: elaboração de análise socioambiental participativa; e construção de metodologia de monitoramento de indicadores socioambientais participativos. O Estudo da realidade geográfica e socioambiental local realizado pelo programa de extensão diagnóstico citado subsisiou alguns planos de ensino do Programa de Honra.

O desafio colocado para a equipe multidisciplinar envolvida no programa foi de conciliar a formação formal - ensino de graduação e pós-graduação - e informal - vivências concretas da realidade dos educandos para pensar o desenvolvimento territorial sustentável, considerando as questões de desenvolvimento frente aos desafios da interdisciplinaridade.

Neste contexto, a universidade assumiu papel fundamental na elaboração e implementação de projetos voltados ao ecodesenvolvimento, fortalecendo suas relações com a comunidade, integrando ensino, pesquisa e extensão, desenvolvendo conhecimentos por meio de projetos de ação territorial. Desta parceria surgiram inúmeros relatórios de estágio, projetos de extensão e pesquisa, dissertações de mestrado e a tese de doutorado realizadas no litoral Centro Sul do Paraná, na Zona de Educação para o Ecodesenvolvimento (ZEE). A ZEE foi criada em 2006, na Microbacia Hidrográfica de Rio Sagrado, no litoral Sul do Paraná, cujo território abriga cerca de 520 famílias, muitas em situação de vulnerabilidade econômica e social, como demonstram resultados do diagnóstico socioparticipativo (Pasco, 2011).

O território em questão integra a Área de Proteção Ambiental (APA) de Guaratuba e os principais objetivos desta ZEE são manutenção dos modos de vida tradicionais e preservação da biodiversidade. Inicialmente, a pesquisa buscou identificar na Zona de Educação para o Ecodesenvolvimento do Litoral do Paraná (Rio Sagrado, Morretes), quais relatórios de estágio, trabalhos de conclusão de curso de graduação, dissertações de mestrado e tese de doutorado foram realizados ou estão em andamento na região delimitada para pesquisa. Organizou-se as informações de maneira que se produziu a Tabela 1, no qual se destaca título do trabalho produzido, palavras-chaves em questão e ano de conclusão do trabalho.

É possível observar na Tabela 1 que prevalecem como palavras chaves nos relatórios de estágio, dissertações e tese pesquisados, as denominações "Ecodesenvolvimento" e "Arranjo socioprodutivo de base comunitária", além de derivações importantes destes termos, como por exemplo: desenvolvimento sustentável, comércio justo, territorialidade e identidade territorial. A pesquisa também identificou outros aspectos importantes relacionados à produção científica da região pesquisada, os quais destacam-se a seguir:

Em relação à natureza das pesquisas identificou-se 3 (três) relatórios de estágio de cursos de graduação, 12 (doze) trabalhos originados de dissertações de mestrado e 01 (uma) tese de doutorado em andamento. Destes trabalhos 14 (quatorze) são oriundos da Universidade Regional de Blumenau (FURB), 01 (um) trabalho da Universidade Federal do Paraná (UFPR) e 01 (um) trabalho da Universidad Austral de Chile (UACH).

5 O termo ecossocioeconomia surge a partir da obra do economista ecológico Karl William Kapp (1963). O primeiro prefixo "Eco" (Oikos = Casa) refere-se à ecologia e reforça o sentido a que o segundo prefixo "eco" deveria remeter. Todavia, este foi vulgarizado ao longo da história ao remeter seu significado ao que Aristóteles já denunciava como crematística. A ecossocioeconomia está imbricada na discussão sobre o ecodesenvolvimento, entendido como antecedente do desenvolvimento sustentável. (Sampaio et al., 2010b). 
TABELA 1 - Relatórios de Estágio, Dissertações e Tese na área delimitada para a pesquisa.

\begin{tabular}{|c|c|c|}
\hline Título do Trabalho & Palavras-Chaves & $\begin{array}{c}\text { Ano de } \\
\text { defesa }\end{array}$ \\
\hline \multicolumn{3}{|l|}{ RELATÓRIOS DE ESTÁGIO } \\
\hline $\begin{array}{l}\text { Arranjo socioprodutivo de base comunitária, com ênfase no turismo } \\
\text { comunitário: o caso da microbacia do Rio Sagrado (Morretes-PR) }\end{array}$ & $\begin{array}{l}\text { Arranjo socioprodutivo de base comunitária. Turismo } \\
\text { comunitário. Desenvolvimento sustentável }\end{array}$ & 2007 \\
\hline $\begin{array}{l}\text { Feria de trueque y agrosistemas tradicionales: } \\
\text { organización y generación de antecedentes para un } \\
\text { Diagnóstico participativo }\end{array}$ & - & 2007 \\
\hline
\end{tabular}

\section{DISSERTAÇÕES}

Arranjo Socioprodutivo de Base Comunitária (APL.COM). Um projeto Arranjo socioprodutivo de base comunitária (APL. piloto na comunidade do entorno da microbacia do Rio Sagrado Com); Comércio Justo.

(Morretes-PR)

A construção participativa de indicadores territoriais socioambientais Desenvolvimento e sustentabilidade; indicadores

para o desenvolvimento regional sustentável. Análise propositiva para socioambientais; Pesquisa ação participante;

as comunidades do Rio Sagrado, Morretes (PR): Zona de educação para microbacia hidrográfica do Rio Sagrado

o ecodesenvolvimento

Tecnologias apropriadas: Pensando o ecodesenvolvimento- Tecnologia apropriada; Ecodesenvolvimento 2009

Experimentação na Microbacia do Rio Sagrado -PR

Políticas Públicas e/ou ações institucionais: as possibilidades para o Ecodesenvolvimento; Políticas públicas; Arranjos desenvolvimento das comunidades do entorno da microbacia do Rio institucionais

Sagrado (Morretes / PR)

Lazer, Territorialidade e Sustentabilidade na microbacia das Comunidade, Desenvolvimento, Lazer, comunidades do Rio Sagrado, Morretes-PR Sustentabilidade, Territorialidade

Análise socioambiental participativa: indicativos de vulnerabilidade Ações participativas; conhecimento cientifico;

ambiental na microbacia hidrográfica do Rio Sagrado - Morretes-PR

sabedoria tradicional, mapeamento; vulnerabilidade ambiental; microbacia hidrográfica; Rio Sagrado.

Planejamento territorial: uma metodologia de monitoramento de Indicadores socioambientais; território;

indicadores socioambientais na microbacia hidrográfica do Rio Sagrado planejamento, desenvolvimento sustentável

- Morretes-PR

Estratégias de desenvolvimento territorial sustentável: o caso da Empresa social; Solidarium; Comércio Justo; Arranjo

Socioprodutivo de Base Comunitária; Turismo

Comunitário

Programa de honra em estudos e práticas em ecossocioeconomia: uma Educação para o ecodesenvolvimento; Programa de

contribuição para a zona de educação para o ecodesenvolvimento na honra; impactos territoriais; interdisciplinaridade localidade de Rio Sagrado - município de Morretes (PR)

Identidade como valor simbólico no processo de desenvolvimento Identidade territorial; projetos de ação; processo de territorial da microbacia hidrográfica do Rio Sagrado - Morretes- PR desenvolvimento; ecodesenvolvimento

O olhar da comunidade sobre o Arranjo Socioprodutivo de Turismo Arranjo socioprodutivo de base comunitária.

de base comunitária em Morretes (PR): vivências, experiências e aprendizados

Sistemas Agroflorestais: estratégia para o desenvolvimento territorial Sistemas agroflorestais. Desenvolvimento territorial familiar.

\section{TESE}

Projetos de desenvolvimento: processos de ensino-aprendizagem ou processos de instrumentalização? (tese em andamento)

Desenvolvimento territorial sustentável; Educação para o ecodesenvolvimento; Educação para o cooperativismo

FONTE: Organizada pelos autores com base na pesquisa bibliométrica. 
$\mathrm{Na}$ Universidade Regional de Blumenau, os trabalhos têm origem em dois cursos de graduação e três programas de Pós-Graduação: Curso de Turismo e Lazer do Centro de Ciências Sociais Aplicadas e Curso de Engenharia Florestal do Centro de Ciências Tecnológicas com 02 (dois) relatórios de estágio. Programa de Pós-Graduação em Desenvolvimento Regional (PPGDR) que desenvolveu 10 (dez) dissertações concluídas e 01 (uma) tese que está em andamento; os Programas de Pós-Graduação em Administração e em Engenharia Ambiental que desenvolveram ambos 01 (uma) dissertação cada. $\mathrm{Na}$ Universidade Federal do Paraná (UFPR) foi desenvolvida 01 (uma) dissertação de mestrado no Programa de Pós-Graduação em Meio Ambiente e Desenvolvimento (MADE) e na Universidad Austral de Chile - Escuela de Antropología (Faculdad de Filosofía y Humanidades) foi desenvolvido 01 (um) relatório de estágio.

Cabe aqui destacar a importante contribuição das universidades na produção científica. As universidades podem oferecer subsídios relevantes para a transformação em grande escala nos padrões culturais dominantes (Vieira \& Fontan, 2011). As atividades das universidades se aplicam a "agentes de mudança" para descrever quatro caminhos de ação universitária de apoio do desenvolvimento territorial:

(a) fornecer um modelo de práticas sustentáveis para a sociedade e estudantes (b) ensinar a lidar com problemas complexos e exercícios de sistema de pensamento; (c) realizar práticas baseadas em pesquisa-atividades, e (d) promover e reforçar a colaboração entre indivíduos e universidades situados como agentes transdisciplinares (Peer \& Stoeglehner, 2013, p. 87.)

É principalmente no contexto da pesquisa e extensão que é possível observar essa importância. Para discutir e implementar estratégias de desenvolvimento territorial local/regional eficientes, o primeiro passo é qualificar as pessoas envolvidas nestas discussões. Neste contexto, os programas de pós-graduação strictu sensu desempenham papel fundamental.

A pesquisa torna-se atividade ao mesmo tempo pedagógica e política, com viés emancipador e empoderador de grupos socialmente excluídos. O principal desafio é tornar indivíduos, grupos sociais e comunida- des locais cada vez mais aptos a aprender, compreender e fazer frente aos condicionantes estruturais da crise contemporânea do meio ambiente e das concepções dominantes do fenômeno do desenvolvimento (Vieira \& Fontan, 2011, p. 27).

Além de identificar os trabalhos desenvolvidos na área delimitada, a pesquisa buscou verificar também a formação acadêmica dos alunos de mestrado e doutorado envolvidos. Observou-se formação diversificada com predominância para a graduação em turismo. Dos 14 (quatorze) alunos envolvidos 06 (seis) tem graduação na área de turismo, 02 (dois) em história, 02 (dois) em administração, 01 (um) em engenharia florestal, 01 (um) em engenharia civil e 01 (um) em geografia. O fato dos trabalhos de pesquisa contarem como o envolvimento de alunos de 06 (seis) graduações distintas mostra a importância de trabalhar projetos de maneira multi, inter e transdiciplinarmente, mesmo que transitar por estas abordagens seja um desafio.

Entende-se que as pesquisas identificadas buscam trabalhar de maneira interdisciplinar, na qual consiste na articulação de várias disciplinas para estudar um tema comum. Cada pesquisador se utiliza de sua formação acadêmica, mas também relaciona sua formação com outras áreas do conhecimento, de maneira articulada no âmbito de projetos de pesquisa e extensão.

Os projetos de pesquisa e extensão constituem conjunto de atividades de caráter complementar. Projetos de pesquisa buscam a reflexão e melhoria do processo de ensino/aprendizagem nos cursos de graduação. Projetos de extensão possuem caráter mais educativo, cultural, artístico e/ou científico, desenvolvidos obrigatoriamente por docentes e discentes por meio de ações sistematizadas, voltadas às questões sociais relevantes. Os projetos ora analisados contemplam em todas as suas fases ações conjuntas e interrelacionadas nas áreas de Ensino/Pesquisa/Extensão.

Para Peer \& Stoeglehner (2013), processos de ensino/aprendizagem ajudam a reformular valores, atitudes e conhecimentos de desenvolvimento territorial sustentável e podem criar propriedade em todas as dimensões do arranjo socioprodutivo de base comunitária (APL. Com). Portanto, fornecem processos que permitem a aprendizagem de circuito duplo, e a posse dos resultados dos processos é criada pela comunidade que apoia a implementação da estratégia de desenvolvimento territorial. 
A Tabela 2 destaca os projetos de pesquisa e extensão desenvolvidos na Zona de Educação para o
Ecodesenvolvimento. É possível observar o nome dos projetos, a situação atual e o ano de origem.

TABELA 2 - Projetos de pesquisa e extensão desenvolvidos na Zona de Educação para o Ecodesenvolvimento

Projetos de pesquisa e extensão

Sagrado, zona laboratório de educação para o ecodesenvolvimento.

Análise Socioambiental Partipativa das localidades Candonga e Rio Sagrado de Cima, Microbacia do Rio Sagrado, Morretes (PR), zona laboratório de educação para o ecodesenvolvimento

Diagnóstico socioambiental participativo da Microbacia do Rio Sagrado, Morretes (PR), zona laboratório de educação para o ecodesenvolvimento, um recorte geográfico da Área de Preservação Ambiental (APA) de Guaratuba, Reserva da Biosfera (ReBIO) de Floresta Atlântica.

Avaliação do potencial de dados do sensor quickbird para o planejamento urbano/regional: como etapa da avaliação ambiental estratégica recorte carta topográfica no. 896029 da PMU, 2003

Avaliação do potencial de dados do sensor quickbird para o planejamento urbano/regional: como etapa da avaliação ambiental estratégica recorte carta topográfica no. 896030 da PMU, 2003

Aplicação do Sistema de Informação Geográfica para vulnerabilidade ambiental à Ocupação Humana: localidade Candonga, Microbacia hidrográfica do Rio Sagrado, Morretes (PR), Zona de educação para o ecodesenvolvimento.

Ecossocioeconomia das Organizações: Arranjos Socioprodutivos de Base Comunitária na Finalizado $2009 \quad$ Pesquisa
Microbacia do Rio Sagrado (Morretes, PR)

\begin{tabular}{|c|c|c|c|}
\hline $\begin{array}{l}\text { Análise dos Fatores Físico Naturais e Antrópicos da localidade de Rio Sagrado de Cima, Microbacia } \\
\text { do Rio Sagrado, Morretes (PR), zona laboratório de educação para o ecodesenvolvimento. }\end{array}$ & Finalizado & 2009 & Pesquisa \\
\hline $\begin{array}{l}\text { Análise dos Fatores Físico Naturais e Antrópicos da localidade Candonga, Microbacia do Rio } \\
\text { Sagrado, Morretes (PR), zona laboratório de educação para o ecodesenvolvimento }\end{array}$ & Finalizado & 2009 & Pesquisa \\
\hline $\begin{array}{l}\text { História da ocupação humana e do uso da natureza na microbacia hidrográfica do Rio Sagrado } \\
\text { (Morretes, Paraná, Brasil) }\end{array}$ & Finalizado & 2009 & Pesquisa \\
\hline
\end{tabular}

Fortalecimento do Turismo de Base Comunitária na conservação de modos de vidas de Finalizado 2009/2010 Extensão comunidades tradicionais e preservação da biodiversidade nas comunidades de Rio Sagrado, Morretes (PR): Interconectando Turismo Comunitário com redes de Comércio Justo

Monitoramento de Indicadores Socioambientais para a Gestão Territorial Participativa da Finalizado 2009/2010 Extensão Microbacia do Rio Sagrado, zona de educação para o ecodesenvolvimento

Projeto de extensão rural com base em Análise Socioambiental Partipativa nas localidades Candonga e Rio Sagrado de Cima, Canhembora e Brejumirim, Microbacia Hidrográfica do Rio Sagrado, Morretes (PR), zona laboratório de educação para o ecodesenvolvimento

\begin{tabular}{|c|c|c|c|}
\hline $\begin{array}{l}\text { Projeto encontros comunitários de trocas, resgate de antigas formas de escambos, para enfrentar } \\
\text { os novos desafios ecossocioeconômicos do século XXI }\end{array}$ & Finalizado & $2009 / 2010$ & Extensão \\
\hline $\begin{array}{l}\text { Programa de extensão rural - Fortalecimento dos modos de vida das populações locais: } \\
\text { Oportunizando conhecimento aos jovens da comunidades do sudoeste da microbacia hidrográfica } \\
\text { do Rio Sagrado, Morretes (PR). zona de educação para o ecodesenvolvimento, um recorte } \\
\text { geográfico da Área de Preservação Ambiental (APA) de Guaratuba, Reserva da Biosfera (ReBIO) } \\
\text { de Floresta Atlântica. }\end{array}$ & Finalizado & $2009 / 2010$ & Extensão \\
\hline $\begin{array}{l}\text { Aplicação do Sistema de Informação Geográfica para Avaliação da Vulnerabilidade Ambiental } \\
\text { à Ocupação Humana: Localidade de Canhembora, Micro Bacia hidrográfica do Rio Sagrado, } \\
\text { Morretes (PR), Zona de Educação para o Ecodesenvolvimento. }\end{array}$ & Finalizado & 2010 & Pesquisa \\
\hline
\end{tabular}

(Continua) 
TABELA 2 - Conclusão

\section{Projetos de pesquisa e extensão}

Situação

Aplicação do Sistema de Informação Geográfica para vulnerabilidade ambiental à Ocupação Humana: localidade Candonga, Microbacia hidrográfica do Rio Sagrado, Morretes (PR), Zona de educação para o ecodesenvolvimento.

Aplicação do Sistema de Informação Geográfica para Avaliação da Vulnerabilidade Ambienta à Ocupação Humana: Localidade de Rio Sagrado de Cima, Microbacia hidrográfica do Rio Sagrado, Morretes- PR), Zona de Educação para o Ecodesenvolvimento.

Monitoramento de Indicadores Socioambientais Territoriais Participativos para o desenvolvimento regional sustentável, da Microbacia Hidrográfica do Rio Sagrado, Morretes (PR), zona de educação para o ecodesenvolvimento.

Análise dos Fatores Físico-Naturais da microbacia hidrográfica do Rio Sagrado de Cima, Morretes (PR), zona de educação para o ecodesenvolvimento.

Análise Ambiental Integrada dos Fatores Físico-Naturais e Antrópicos da Microbacia Hidrográfica Fin do Rio Sagrado, Morretes (PR), Zona De educação para o ecodesenvolvimento

Análise Ambiental Integrada dos Fatores Físico-Naturais e Antrópicos da localidade de Pitinga, na Microbacia Hidrográfica do Rio Sagrado, Morretes (PR), Zona De educação para o ecodesenvolvimento.

\begin{tabular}{|c|c|c|c|}
\hline $\begin{array}{l}\text { Análise Ambiental Integrada dos Fatores Físico-Naturais e Antrópicos da localidade de } \\
\text { Sambaqui na Microbacia Hidrográfica do Rio Sagrado, Morretes (PR), Zona De educação para } \\
\text { o ecodesenvolvimento }\end{array}$ & Finalizado & 2011 & Pesquisa \\
\hline $\begin{array}{l}\text { Análise Ambiental Integrada dos Fatores Físico-Naturais e Antrópicos da localidade de } \\
\text { Zoador na Microbacia Hidrográfica do Rio Sagrado, Morretes (PR), Zona De educação para o } \\
\text { ecodesenvolvimento }\end{array}$ & $\begin{array}{c}\text { Em } \\
\text { elaboração }\end{array}$ & 2011 & Pesquisa \\
\hline $\begin{array}{l}\text { Projeto de extensão: Processo Pedagógico Emancipatório, Zonas de Educação para o } \\
\text { ecodesenvolvimento, Reserva da Biosfera de Mata Atlântica. }\end{array}$ & Duplicado & 2013-2014 & Extensão \\
\hline $\begin{array}{l}\text { Projeto de extensão: Processo de construção de competências para projetos de ação territorial, } \\
\text { Zona de Educação para o ecodesenvolvimento na Microbacia hidrográfica do Rio Sagrado, } \\
\text { Morretes, (PR), recorte geográfico da Área de Preservação Ambiental (APA) de Guaratuba, } \\
\text { Reserva da Biosfera (ReBIO) de Floresta Atlântica. }\end{array}$ & Finalizado & 2013-2014 & Extensão \\
\hline $\begin{array}{l}\text { Programa de extensão: Região Laboratório de Educação para o Ecodesenvolvimento do Litoral } \\
\text { Centro Sul do Paraná (Morretes) e Litoral Extremo Norte de Santa Catarina (Itapoá). }\end{array}$ & Finalizado & $2013-2014$ & Extenção \\
\hline Como desenvolver competências por meio da construção de projetos locais? (CNPq) & $\begin{array}{c}\text { Em } \\
\text { execução }\end{array}$ & $2014 / 2015$ & Pesquisa \\
\hline $\begin{array}{l}\text { A participação da fisioterapia no desenvolvimento territorial sustentável da Microbacia do Rio } \\
\text { Sagrado, zona de reserva ambiental da mata atlântica, município de Morretes-PR }\end{array}$ & Finalizado & 2014 & Pesquisa \\
\hline $\begin{array}{l}\text { Promoção de saúde e qualidade de vida para o desenvolvimento territorial sustentável: Um } \\
\text { estudo comparativo entre os municípios de Morretes/PR e Doutor Pedrinho/SC baseado nos }\end{array}$ & $\begin{array}{c}\text { Em } \\
\text { execução }\end{array}$ & 2014-2015 & Pesquisa \\
\hline
\end{tabular}

2010

Pesquisa

Finalizado

2010

Pesquisa

Finalizado

2010

Pesquisa

Finalizado

2010

Pesquisa

Finalizado

2011

Pesquisa

Finalizado

2011

Pesquisa

Análise Ambiental Integrada dos Fatores Físico-Naturais e Antrópicos da localidade de Sambaqui na Microbacia Hidrográfica do Rio Sagrado, Morretes (PR), Zona De educação para o ecodesenvolvimento

Análise Ambiental Integrada dos Fatores Físico-Naturais e Antrópicos da localidade de Zoador na Microbacia Hidrográfica do Rio Sagrado, Morretes (PR), Zona De educação para o ecodesenvolvimento

Projeto de extensão: Processo Pedagógico Emancipató
ecodesenvolvimento, Reserva da Biosfera de Mata Atlântica.

Projeto de extensão: Processo de construção de competências para projetos de ação territorial,

Reserva da Biosfera (ReBIO) de Floresta Atlântica.

FONTE: Organizada pelos autores através de dados obtidos do Sistema de Pesquisa e Extensão da FURB. Disponível em: http://www.furb.br/ web/1004/inovacao-e-pesquisa. Acesso: novembro de 2014. 
Observa-se na Tabela 2, um total de 30 (trinta) projetos, sendo 11 (onze) projetos de extensão e 19 (dezenove) projetos de pesquisa, a maioria destes utilizou o termo "educação para o ecodesenvolvimento". Os projetos se inserem em quatro propostas maiores, todas financiadas: Projeto de extensão da FURB, com finanacimento da própria IES: Diagnóstico socioambiental participativo da Microbacia do Rio Sagrado, Morretes (PR), Zona de educação para o ecodesenvolvimento, recorte geográfico da Área de Preservação Ambiental (APA) de Guaratuba, Reserva da Biosfera (ReBIO) de Floresta Atlântica. Projetos de pesquisa/extensão da FURB com financiamento do Ministério do Turismo: Fortalecimento do turismo de base comunitária na conservação dos modos de vida de comunidades tradicionais e preservação da biodiversidade na comunidade de Rio Sagrado, Morretes/PR; Projeto de Extensão da FURB, com financiamento do Ministério da Cultura: Projeto encontros comunitarios de trocas, resgate de antigas formas de escambos para enfrentar os novos desafios ecossocioeconômicos. Edital chamada MCTI/CNPQ/ MEC/CAPES no 43/2013 - Programa de Pós-Graduação (PPG) em Gestão Urbana/PUC-PR e colaboração do PPG em Desenvolvimento Regional/FURB: Núcleo de Políticas Públicas.

Destes trabalhos resultaram projetos como: curso pré-vestibular vocacionado, caminhadas geoambientais utilizando como base cartografia e maquete para planejar incursões a campo com objetivo de levantar e correlacionar informações de maneira multidisciplinar e oficinas de identidade de gastronomia com palmito juçara, gastronomia com banana.

Foi possível observar que os projetos implementados ao longo dos anos-possibilitaram envolvimento dos atores sociais, permitindo a construção de saberes e de competências, demonstrando a indissociabilidade entre pesquisa e extensão. Foram desenvolvidos processos pedagógicos interdisciplinares combinando aspectos teóricos de produção de conhecimento, como aspecto metodológico de oferta de métodos de aprendizagem, e finalmente de aplicação, na definição conjunta das ferramentas necessárias para a ação.

\section{Considerações finais}

O desenvolvimento territorial não compreende apenas a questão geográfica ou econômica, mas atores e interrelação destes atores na promoção do desenvolvimento. A construção dessas interrelações é um desafio que pode ser superado por meio da formação de arranjos institucionais eficientes, cujo objetivo é promover o desenvolvimento no território contemplando as cinco dimensões de sustentabilidade do ecodesenvolvimento defendidas por Sachs (1993): econômica, social, ecológica, espacial e cultural. Ocorre que estas dimensões sugerem tratamento inter, multi e transdisciplinar dos projetos de pesquisa e extensão, e transitar por estas abordagens constitui-se outro desafio.

O objetivo do artigo foi sistematizar o esforço de pesquisa ao redor de uma Zona de Educação para o Ecodesenvolvimento (ZEE), no litoral centro sul do Paraná, e analisar o papel da universidade enquanto indutor de desenvolvimento territorial. Identificou-se o empenho de pesquisa-ação participativa, no qual relevaram-se saberes locais, em um processo cooperativo e interativo quanto a problematização e alternativas de solução. Deste modo, ações conjuntas entre pesquisadores e comunidade entrelaçaram conhecimento científico e tradicional a partir da perspectiva de indissiocibilidade entre ensino, pesquisa e extensão, priorizando a educação como uma prática propositiva.

Neste contexto surge o papel das universidades como agente de mudanças, por meio de seus programas de pós-graduação stricto sensu que podem se utilizar dessas abordagens para intervir em ambientes fragilizados, promover o desenvolvimento territorial sustentável e contribuir para melhoria da qualidade de vida da população autóctone. Além disso, universidades funcionam: “(1) como motores principais para iniciar certas ações dentro dos processos de desenvolvimento sustentável, (2) como facilitadoras ao acesso à rede regional, e (3) como ponte entre instituições e os diferentes intervenientes, mas também como reforço do capital social regional". (Devine-Wright et al., 2001, p. 161-167). 
A produção elencada e analisada demonstra a importância da participaççao das universidades nas discussões locais e regionais relacionadas ao desenvolvimento. Na Zona de Educação para o Ecodesenvolvimento verificou-se importante papel desenvolvido pelas Universidades, principalmente por meio de Programas de Pós- Graduação stricto sensu, e pelas agências de financiamento, a partir de iniciativas de promoção de potencialidades locais, melhorando a qualidade de vida da população.

Principais determinantes do impacto das Universidades que atuam como agentes de transformação no desenvolvimento territorial por meio de Arranjos socioprodutivos de base comunitária (APL.Com.) são a oportunidade de maturar o conhecimento disponibilizado e de criar formas colaborativas de pesquisa e educação em ambientes de aprendizagem informal para que a demanda, transferência e geração de conhecimento possam ser fomentadas conjuntamente entre comunidades locais, arranjos microrregionais e universidades.

Os projetos desenvolvidos pelos Programas de Pós-Graduação são exemplo de que é possível integrar teoria e prática e contribuir efetivamente para o desenvolvimento local e regional de localidades fragilizadas. O objetivo principal do subprojeto educação para o ecodesenvolvimento com enfoque interdisciplinar está em aproximar a universidade da rede pública de ensino básico e favorecer a formação de competências em gestão de projetos locais, orientada para projetos de melhoramento da qualidade do meio ambiente de vida.

A Universidade se esforça para não instrumentalizar seus objetivos individuais de pesquisa, sejam eles

\section{Referências}

Abramovay, R. Para uma teoria dos estudos territoriais. In: Vieira, P. F; Cazella, D.; Cerdan, C.; Carrière, P.; (Orgs.). Desenvolvimento territorial sustentável no Brasil: subsídios para uma política de fomento. Florianópolis: APED, Secco. 2010. 448p.

Asseburg, H. B.; Gaiger, L. I. A economia solidária e a redução das desigualdades. Grupo de Pesquisa em Economia Solidária - Ecosol. CNPq, FAPERGS, 2007, UNESCO. oriundos de trabalhos de conclusão de curso de graduação e pós-graduação, dialogando com a comunidade local, dando ênfase na pesquisa-ação participativa, que requer antes de tudo, imbricamento, vivência com os modos de vida, de produção e de conhecimento que se quer conservar.

Como conclui Boff (1999, p. 33): "Cuidar é mais que um ato, é uma atitude. [...] representa uma atitude de ocupação, preocupação, de responsabilização e envolvimento afetivo com o outro". Enfim, o ser humano como ser social e histórico é fruto de suas relações entre seus pares, e também com a natureza, o que possibilita troca de afetos, experiências de vida, o que é fundamental para a experiência interdisciplinar com vocação transdisciplinar, no sentido de retroalimentar o movimento de construção e desconstrução de nossa identidade como das comunidades e territórios.

Deste modo, a Universidade, por meio de processos de aprendizagem, possibilita a construção de competências, utilizando processos de pesquisa-ação que desencadeam dinâmicas que acabam gerando sinergias, resultado da convivência entre pesquisadores e a própria comunidade.

Os projetos de pesquisa e extensão, relatórios de estágio, dissertações e tese resultantes desta interação, contribuem decisivamente para o desenvolvimento de aprendizagens tácitas e interações de fortalecimento coletivo da comunidade local, permitindo produção de conhecimento entre dois mundos: acadêmico e comunidade de aprendizagem, superando o desafio do desenvolvimento territorial, traduzindo reflexões e orientações em ações concretas.
Baroni, M. Ambigüidades e deficiências do conceito de sustentabilidade. RAE, 32(2), 14-24, 1992.

Becker, B. K.; Santos, M. Território, territórios, ensaios sobre o ordenamento territorial. São Paulo: Lamparina, 2007.

Beduschi Filho, L. C.; Abramovay, R. Desafio para o desenvolvimento das regiões rurais. Nova Economia, 14(3), 35-70, 2004. 
Boff, L. Saber cuidar: ética do humano? compaixão pela terra. Petrópolis, RJ: Vozes, 1999.

Boydb, J.; Banzhaf, S. What are ecosystem services? The need for standardized environmental accounting units. Ecological Economics, 63, 616-626, 2007.

Caldas, A. S. As denominações de origem como unidade de planejamento, desenvolvimento local e inclusão social. $R D E$ - Revista de Desenvolvimento Econômico, 5(8), 25-32, 2003.

Carriére, J. P.; Cazella, A. A. Abordagem introdutória ao conceito de desenvolvimento territorial. EISFORIA, 4, 23-47, 2006.

Conferência das Nações Unidas Sobre Meio Ambiente e Desenvolvimento (CNUMAD). Agenda 21. Disponível em: http:// www.mma.gov.br/responsabilidade-socioambiental/agenda-21/agenda-21-global. Acesso em: 25 de março de 2014.

Costa, E. J. M. da. Políticas públicas e o desenvolvimento de arranjos produtivos locais em regiões periféricas. Campinas, SP: [s.n.]. 409 f. Tese (Doutorado em Desenvolvimento Econômico). Universidade Estadual de Campinas, 2007.

Coudel, E.; Tonneau, J-P. Formação para o desenvolvimento territorial sustentável: subsídios para a produção de conhecimentos úteis e utilizáveis. In: Vieira, P. F; Cazella, D.; Cerdan, C.; Carrière, P. (Orgs.). Desenvolvimento territorial sustentável no Brasil: subsídios para uma política de fomento. Florianópolis: APED, Secco. 2010. 448p.

Dallabrida, V. R. O desenvolvimento regional. Rio Grande do Sul. Ijuí: UNIJUÍ, 2000.

Devine-Wright, P.; Fleming, P. D.; Chadwick, H. Role of social capital in advancing regional sustainable development. Impact Assessment and Project Appraisal. 19 (2), 2001.

Fisher, B.; Turner, R. K.; Morling, P. Defining and classifying ecosystem services for decision making. Ecological Economics, 68, 643-653, 2009.

Freitas Santos, J.; Cadima Ribeiro, J. Estratégias empresariais de base territorial: o caso Symington e a produção de vinho do Porto. Revista Desenvolvimento Regional em Debate, 2(1), 134-155, 2012.

Garcia, R. Interdisciplinaridad y systemas complejos. In: Leef, E. (Org.). Ciencias Sociales y Formulación Ambiental. Barcelona: Gedisa p. 85-125, 1994.

Jean, B. Do desenvolvimento regional ao desenvolvimento territorial sustentável: rumo a um desenvolvimento territorial solidário para um bom desenvolvimento dos territórios rurais.
In: Vieira, P. F; Cazella, D.; Cerdan, C.; Carrière, P.; (Orgs.). Desenvolvimento territorial sustentável no Brasil. Florianópolis: APED: SECCO, 2010.

Kapp K. W. The Social Costs of Business Enterprise. Spokesman Books, Nottingham, 1963.

Lastres, H. M. M. Avaliação das políticas de promoção de arranjos produtivos locais no Brasil e proposições de ações. Rio de Janeiro: 2007.

Lastres, H. M. M.; Cassiolato, J. E. O foco em arranjos produtivos e inovativos locais de micro e pequenas empresas. In: Lastres, H. M. M.; Cassiolato, J. E.; Maciel, M. L. (Orgs.). Pequena empresa: cooperação e desenvolvimento local. Rio de Janeiro: RelumeDumará, 2003a, p. 21-34.

Lastres, H. M. M.; Cassiolato, J. E. Novas políticas na era do conhecimento: o foco em arranjos produtivos e inovativos locais. Parcerias Estratégicas, 7, 5-29, 2003 b.

Laville, J. L. Fato associativo e economia solidária. In: Superintendência de Estudos Econômicos e Sociais da Bahia, SEI. Rev. Bahia: análise e dados. Salvador, v. 12, n. 1, junho 2002, p. 25-34.

Leff. E. Ecologia, capital e cultura. Blumenau: EDIFURB, 2000.

Leff. E. Racionalidade ambiental: a representação social da natureza. Rio de Janeiro: Civilização Brasileira, 2006.

Lenzen, M.; Murray, J.; Sack, F.; Wiedmann, T. S. Shared producer and consumer responsibilility - Theory and practice. Ecological Economics, 61(1), 27-42, 2006.

Leveque C. ; Pave, A.; Abbadie, L.; Weill, A.; Vivien, F. D. Les zones ateliers, des dispositifs pour la recherche sur l'environnement et les anthroposystèmes. Nature, Sciences, Sociétés, 8(4), 44-52, 2000.

Morin, E. Ciência com consciência. Rio de Janeiro: Bertrand Brasil, 1996.

Morin, E. A cabeça bem feita: repensar a reforma, reformar o pensamento. $8^{\text {a }}$ ed. Rio de Janeiro: Bertrand Brasil, 2003.

Ortega, A. C.; Jeziorny, D. L. Vinho e território. A experiência do Vale dos Vinhedos. Campinas: alínea, 2011.

Paul, P. Pensamento complexo e interdisciplinaridade: abertura para mudança de paradigma? In: Phillipi Junior, A.; Silva Neto, A. Interdisciplinaridade em ciência, tecnologia e inovação. Barueri: Manole, 2011.

Pasco, A. D. Programa de honra em estudos e práticas em ecossocioeconomia: uma contribuição para a zona de educação 
para o ecodesenvolvimento na localidade de Rio Sagrado município de Morretes (PR). 115 f. Dissertação (Mestrado em Desenvolvimento Regional). Fundação Universidade Regional de Blumenau, 2011.

Pecqueuer, B. O desenvolvimento territorial: Uma nova abordagem dos processos de desenvolvimento para as economias do sul. Raizes, 24(1 e 2), 10-22, 2005.

Peer. V.; Stoeglehner, G. Universities as change agents for sustainability - framing the role of knowledge transfer and generation in regional development processes. Journal of Cleaner Production, 44, 85-95, 2013.

Raud, C. O ecodesenvolvimento e o desenvolvimento territorial: problemáticas cruzadas. In: Vieira, P. F.; Ribeiro, M. A.; Franco, R. M.; Cordeiro, R. C. (Org.). Desenvolvimento e meio ambiente no Brasil: a contribuição de Ignacy Sachs. Porto Alegre: Pallotti \& APED,1998.

Sacco dos Anjos, F.; Caldas, N. V.; Silva, F. N.; Pollnow, G. E. Sobre 'efígies e esfinges': indicações geográficas, capital social e desenvolvimento territorial. In: Dallabrida, V. R. (Org.). Território, identidade territorial e desenvolvimento regional: reflexões sobre indicação geográfica e novas possibilidades de desenvolvimento com base em ativos com especificidade territorial. São Paulo-SP: LiberArs, 2013.

Sachs, I. Environment et planification: quelques pistes de recherches et d'action. In: Environment and Planning: Some Areas of Research and Action. Information sur les Sciences Sociales 13, 6, 17-29, 1974.

Sachs, I. Ecodesenvolvimento.Crescer sem destruir. São Paulo: Vértice, 1986a.

Sachs, I. Espaços, tempos e estratégias de desenvolvimento. São Paulo:Vértice, 1986b.

Sachs, I. Estratégias de transição para o século XXI: desenvolvimento e meio ambiente. São Paulo: Estúdio Nobel, 1993.

Sachs, I. Inclusão social pelo trabalho: desenvolvimento humano, trabalho decente e o futuro dos empreendedores de pequeno porte. Rio de Janeiro: Garamond, 2003.

Sachs, I. Rumo à ecossocioeconomia: teoria e prática do desenvolvimento. São Paulo: Cortez, 2007.

Sampaio, C. A. C. (Org.). Gestão que privilegia uma outra economia: ecossocioeconomia das organizações. Blumenau: Edifurb, 2010a.

Sampaio, C. A. C.; Araujo, J. R.; Dias, A.; Zuniga, C. E. H.; Souza, C. M. M. Educación para el ecodesarrollo: micro-cuenca del Río Sagrado. In: Congresso Chileno de Antropologia,
2010, Valdivia. Congresso Chileno de Antropologia, 2010.

Sampaio, C. A. C.; Dallabrida, I. S.; Pellin, V. Para pensar a socioeconomia das organizações: estudo comparativo de uma experiência incipiente brasileira com um projeto demonstrativo chileno. Revista paranaense de desenvolvimento, 109, 49-80, 2005.

Sampaio, C. A. C; León, I. C.; Dallabrida, I. S.; Pellin, V. Arranjos Socioprodutivos de Base Comunitária: arranjos produtivos locais pensados como arranjos institucionais. O caso da Mondragón Corporação Cooperativa. Revista Organização e Sociedade. 15(46), 77-98, 2008.

Schneider, J. O. Globalização, desenvolvimento local sustentável e cooperativismo. Programa de Pós-Graduação em Ciências Sociais Aplicadas. Instituto Humanitas, UNISINOS/ RS, 2004 (Paper).

Singer, P. Economia solidária: um modo de produção e distribuição. In: Singer, P.; Souza; A. R.; (Orgs) A economia solidária no Brasil: a autogestão como resposta ao desemprego. São Paulo: Contexto, 2000.

Vieira, P. F. A problemática ambiental e as ciências sociais no Brasil (1980-1990). In: Hogan, D. J.; Vieira, P. F. (Orgs.). Dilemas socioambientais e desenvolvimento sustentável. Campinas: Editora da UNICAMP, 1992.

Vieira, P. F. Meio Ambiente, Desenvolvimento e Planejamento. In: Viola, E. J.; Leis, H. R. Leis, Scherer-Warren, I.; Guivant, J. S.; Vieira, P. F.; Krischke, P. J. Meio ambiente, desenvolvimento e cidadania: desafios para as Ciências Sociais. 4.ed. São Paulo: Cortez, 1995.

Vieira, P. F. Repensando a educação para o ecodesenvolvimento. In: Vieira, P. F.; Ribeiro, M. A. (Orgs.). Ecologia humana, ética e educação. A mensagem de Pierre Dansereau. Porto Alegre: Pallotti e Florianópolis: APED, 1999.

Vieira, P. F. Ecodesenvolvimento: do conceito a ação, de Estocolmo a Joanesburgo. In: Sachs, I. Rumo à ecossocioeconomia: teoria e prática do desenvolvimento. São Paulo: Cortez, 2007.

Vieira, P. F. Políticas ambientais no Brasil: do preservacionismo ao desenvolvimento territorial sustentável. Revista Política e Sociedade, 27-75, 2009.

Vieira, P. F.; Fontan, J. M. Por um enfoque sistêmico, ecológico e territorializado. In: Tremblay, G.; Vieira, P. F. (Orgs.). $O$ papel da universidade no desenvolvimento local: experiências brasileiras e canadenses. Florianópolis: APEC/SECCO, 2011.

Vieira, P. F.; Raud, C.; Moraes, E. C. de. Uma estratégia de ecodesenvolvimento para a região litorânea Sudeste - Sul do 
Brasil. Programa de pesquisa sobre meios de apropriação e gestão comunitária de recursos naturais. [s.n]; [s.d]. In: Vieira, P. F.; Ribeiro, M. A. (Orgs.). Desenvolvimento e meio ambiente no Brasil: a contribuição de Ignacy Sachs. Porto Alegre: Palotti; Florianópolis: APED, 1998. Disponível em: <http://www. cfh. ufsc.br aped/uma_estratégia_de_edodesenvolvimento.html> Acesso em: 15 jan. 2012.

Vieira, P. F.; Ribeiro, M. A.(Orgs.). Ecologia humana, ética e educação. A mensagem de Pierre Dansereau. Porto Alegre: Pallottie Florianópolis: APED, 1999. 